\title{
Chemical characteristics of poplar type propolis of different geographic origin*
}

\author{
Milena P. Popova ${ }^{\mathrm{a}}$, Vassya S. BANKOVA ${ }^{\mathrm{a}}$, Stefan BogdANOV ${ }^{\mathrm{b}}$, Iva TsVETKOVA ${ }^{\mathrm{c}}$, \\ Christo NAYDENSKI ${ }^{\mathrm{c}}$, Gian Luigi MARCAZZAN ${ }^{\mathrm{d}}$, Anna-Gloria SABATINI ${ }^{\mathrm{d}}$ \\ a Institute of Organic Chemistry with Centre of Phytochemistry, Bulgarian Academy of Sciences, 1113 Sofia, \\ Bulgaria \\ ${ }^{\text {b }}$ Swiss Bee Research Centre, FAM, Liebefeld, 3003 Bern, Switzerland \\ ${ }^{\mathrm{c}}$ Institute of Microbiology, Bulgarian Academy of Sciences, 1113 Sofia, Bulgaria \\ ${ }^{\mathrm{d}}$ National Institute of Beekeeping, 80 Via di Saliceto, Bologna, Italy
}

Received 16 June 2006 - Revised 15 January 2007 - Accepted 22 January 2007

\begin{abstract}
Validated spectrophotometric procedures were used to quantify three main groups of bioactive substances (phenolics, flavones/flavonols, flavanones/dihydroflavonols) in 114 samples of poplar-type propolis from different geographic origins. From the results, we characterized raw poplar propolis in terms of minimum content of its bioactive components (antimicrobial and antioxidant) as follows: $45 \%$ resin, $21 \%$ total phenolics, $4 \%$ total flavones/flavonols; $4 \%$ total flavanones/dihydroflavonols, and a maximum Minimum Inhibitory Concentration (MIC) against $S$. aureus of $250 \mu \mathrm{g} / \mathrm{mL}$. A significant negative correlation was observed between the amount of total phenolics and MIC. The results indicate that measuring the concentrations of groups of active compounds, rather than individual components, is an appropriate approach in developing quality standards for propolis.
\end{abstract}

poplar propolis / chemical characteristics / antibacterial activity / standardization

\section{INTRODUCTION}

Over the last 30 years, the biological activity of propolis, (e.g., its antibacterial, antifungal, antiviral, immunostimulating, antitumor, and antioxidant properties) has been demonstrated by scientific studies (Marcucci, 1995; Banskota et al., 2001; Bankova, 2005a). The use of propolis in folk medicine continues to increase (Castaldo and Capasso, 2002) as a constituent of "bio-cosmetics", "health foods" and for numerous other purposes (Wollenweber and Buchmann, 1997; Banskota et al., 2001). However, chemical studies have revealed chemical variability among propolis samples and the existence of different chemi-

Corresponding author: V.S. Bankova,

Bankova@orgchm.bas.bg

* Manuscript editor: Stefan Fuchs cal types of propolis according to plant source (Bankova, 2005b). In temperate zones all over the world, poplar bud exudates (mainly of Populus nigra L.) have been shown to be the main source of bee collected resin. Undoubtedly, poplar type propolis is the most studied and the best known type of propolis, both from chemical and pharmacological point of view. The chemical constituents responsible for its beneficial biological activities, and especially for its antimicrobial and antioxidant properties, are well documented: flavonoids (including flavones, flavonols, flavanones and dihydroflavonols) and other phenolics (mainly substituted cinnamic acids and their esters) (Banskota et al., 2001). It is important for propolis users, such as companies producing propolis preparations, to know the characteristic concentrations of the above-mentioned constituents of this propolis type to guarantee 
a good quality product and a reasonable degree of antibacterial activity.

Recently, we developed and validated rapid, low-cost spectrophotometric procedures for quantification of the three main groups of bioactive substances in poplar type propolis: total phenolics; total flavones and flavonols; and total flavanones and dihydroflavonols (Popova et al., 2004). In this article we describe the application of these methods to a large number (114) of poplar propolis samples from different geographic origins. We also measured the amount of balsam in these samples. The amount of balsam in propolis is determined by preparing an extract of crude propolis in $70 \%$ ethanol, which is how propolis is usually used in medicine (Greenaway et al., 1991). The amount of balsam extracted from crude propolis is an important characteristic because high percentage of balsam means the propolis contained a low percentage of wax and insoluble matter. Propolis with high balsam content has a higher content of biologically active components (Kujumgiev et al., 1999).

Based on these results, we are able to describe the typical characteristics of poplar propolis in terms of its content of bioactive components. This is of particular interest also with respect to propolis standardization, which is a condition for the official acceptation of propolis in the main stream of the health care system.

\section{MATERIALS AND METHODS}

\subsection{Propolis}

Propolis samples were kindly supplied by the National Institute of Beekeeping (Bologna, Italy), the Swiss Bee Research Centre (Bern, Switzerland), Allwex Company (Hamburg, Germany), Victoria Kamenova Company (Sofia, Bulgaria), Apimell Company (Macedonia), Mr. D. Dimov (Sofia, Bulgaria), Dr. Abdulla (Latakia, Syria), Mr. Houshang Afousan (Teheran, Iran), and Dr. Sibel Silici (Kayzeri, Turkey).

The geographical origin and number of samples analyzed were: Bulgaria (30 samples), Italy (26), Switzerland (10), Syria (10), Turkey (9), Republic of Macedonia (8), Iran (3), and one sample each from Argentina, Canada, Chile, China, England, Estonia, Hungary, Korea, Latvia, Lithuania, New Zealand, Poland, Russia (Siberia), Slovakia, Ukraine, Uruguay, USA, and Uzbekistan for a total of 114 samples.

\subsection{Analysis}

The analysis was essentially performed as described in Popova et al. (2004). In brief, it was carried out as follows:

\subsubsection{Propolis extraction}

Propolis (cooled) was grated and a sample of $1 \mathrm{~g}$ was dissolved in $30 \mathrm{~mL} 70 \%$ ethanol in a $50 \mathrm{~mL}$ flask and left for $24 \mathrm{~h}$ at room temperature. It was then filtered and the extraction was repeated. The two extracts were combined and diluted to $100 \mathrm{~mL}$ with $70 \%$ ethanol in a volumetric flask. They were then analyzed to determine the total phenolics and flavonoids.

\subsubsection{Balsam content}

From each crude sample, three parallel extracts with $70 \%$ ethanol were prepared as described above. Two $\mathrm{mL}$ of each were evaporated to dryness in vacuo until they reached a constant weight, and the percentages of balsam in the extracts were calculated as the ethanol soluble fraction. The mean of the three values was determined.

\subsubsection{Flavone and flavonol content}

A $2 \mathrm{~mL}$ aliquot of the test solution, $20 \mathrm{~mL}$

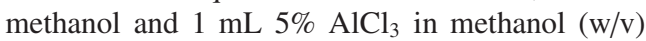
were mixed in a volumetric flask and the volume was made up to $50 \mathrm{~mL}$ with methanol. The mixture was left to rest for $30 \mathrm{~min}$ and the absorbance at $425 \mathrm{~nm}$ was measured. Calibration was performed using galangin as reference compound.

\subsubsection{Flavanone and dihydroflavonol content}

A $1 \mathrm{~mL}$ aliquot of test solution and $2 \mathrm{~mL}$ of 2,4dinitrophenylhydrazine (DNP) solution (1 g DNP 
Table I. Characteristics of poplar propolis samples, based on 114 samples.

\begin{tabular}{lllllllll}
\hline Characterisitcs & $\begin{array}{l}\text { Mean } \\
\text { value }\end{array}$ & Median & $\begin{array}{l}\text { Min. } \\
\text { Value }\end{array}$ & $\begin{array}{l}\text { Max. } \\
\text { value }\end{array}$ & P90* & P80 & P20 & P10 \\
\hline Balsam, \% & 57 & 58 & 18 & 82 & 71 & 67 & 45 & 36 \\
Phenolics, \% & 28 & 27.6 & 7.9 & 46 & 40 & 38 & 21 & 17 \\
Flavones and flavonols, \% & 8 & 8.2 & 1.3 & 17.9 & 13 & 12 & 4 & 3 \\
Flavanones and dihydroflavonols, $\%$ & 6 & 6 & 1.5 & 15.2 & 9 & 8 & 4 & 3 \\
MIC, $\mu$ g.mL mL $^{-1}$ & 210 & 188 & 31.2 & 500 & 500 & 250 & 125 & 62.5 \\
\hline
\end{tabular}

* Percentile.

in $2 \mathrm{~mL} 96 \%$ sulfuric acid, diluted to $100 \mathrm{~mL}$ with methanol in a volumetric flask) were heated at $50{ }^{\circ} \mathrm{C}$ for $50 \mathrm{~min}$ (water bath). After cooling to room temperature the mixture was diluted to $10 \mathrm{~mL}$ with $10 \% \mathrm{KOH}$ in methanol $(\mathrm{w} / \mathrm{v})$. One $\mathrm{mL}$ of the resulting solution was added to $10 \mathrm{~mL}$ methanol and was diluted to $50 \mathrm{~mL}$ with methanol (volumetric flasks). Absorbance was measured at $486 \mathrm{~nm}$. Calibration was performed using pinocembrin as reference compound.

\subsubsection{Total phenolics content}

An aliquot $(1 \mathrm{~mL})$ of the test solution was transferred to a $50 \mathrm{~mL}$ volumetric flask containing $15 \mathrm{~mL}$ distilled water, and $4 \mathrm{~mL}$ of Folin-Ciocalteu reagent and $6 \mathrm{~mL}$ of a $20 \%$ sodium carbonate solution $(\mathrm{w} / \mathrm{v})$ were added. The volume was made up with distilled water to $50 \mathrm{~mL}$. The sample was left for $2 \mathrm{~h}$ and the absorbance at $760 \mathrm{~nm}$ was measured. Calibration was performed using a reference mixture of pinocembrin and galangin, in 2:1 (w/w) for calibration.

\subsubsection{Minimum Inhibitory Concentration against Staphylococcus aureus}

The test strain used was Staphylococcus aureus 209, obtained from the Bulgarian Type Culture Collection, Institute for State control of Drugs, Sofia. The minimum inhibitory concentration (MIC) was determined by the macrodilution tube method (Hadjidimova, 1975). The MIC of the balsam was determined by diluting dry balsam to various concentrations $(0.0-2000 \mu \mathrm{g} / \mathrm{mL})$, using meat-pepton broth in test tubes. Each test tube was inoculated with a bacterial suspension containing $1 \times 10^{6}$ cells per $\mathrm{mL}$ and incubated at $37^{\circ} \mathrm{C}$ for $24 \mathrm{~h}$. The MIC was regarded as the lowest concentration of the extract that did not permit any visible growth when compared with drug free broth inoculated with the bacterial suspension. For more precise detection, tubes that showed no visible growth were streaked on fresh meat-pepton agar plates, incubated at $37^{\circ} \mathrm{C}$ for $24 \mathrm{~h}$ and examined for growth.

\subsubsection{Statistics}

Statistical analysis was performed using STATISTICA for Windows (Stat. Soft. Inc., 1995).

\section{RESULTS}

All samples analyzed were of poplar origin, as confirmed by thin layer chromatography (TLC) test (Popova et al., 2004), using specific marker compounds for poplar propolis (Greenaway et al., 1990; Bankova et al., 2000).

The values of the characteristics, obtained by processing the data from the 114 samples of proved poplar origin, are presented in Table I and the histograms in Figure 1. Data on antibacterial activity (MIC of dry balsam) are also represented. The results obtained for all of the parameters were analyzed by the Shapiro-Wilk normality test. The values were not normally distributed (Fig. 1).

ANOVA statistics were applied to sample groups from countries with three or more samples to determine if there were significant differences in the chemical characteristics of the samples due to geographic origin. After Bonferoni-corrected posthoc pairwise comparisons, some significant differences $(P<0.05)$ were found but they did not follow any distinct geographic pattern. For 


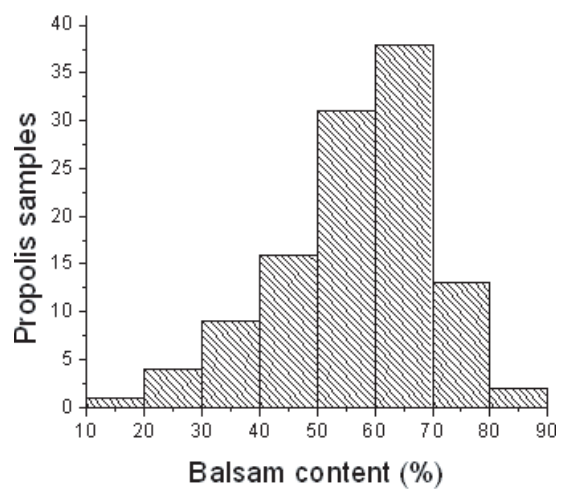

(a)

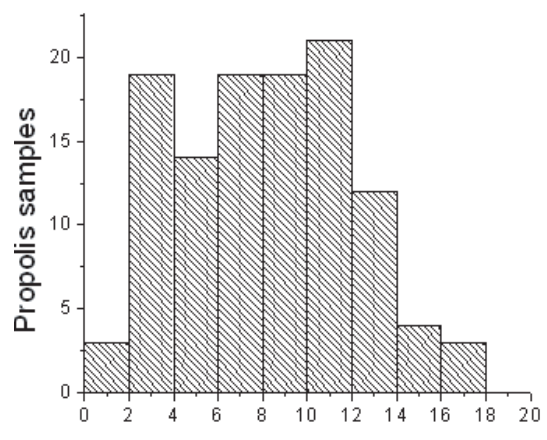

Total flavones and flavonols content (\%)

(c)

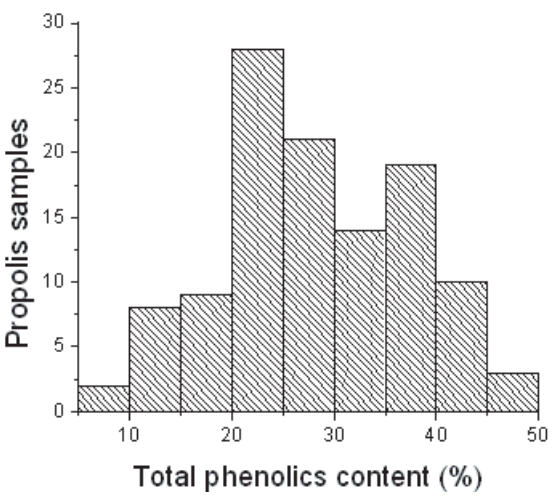

(b)

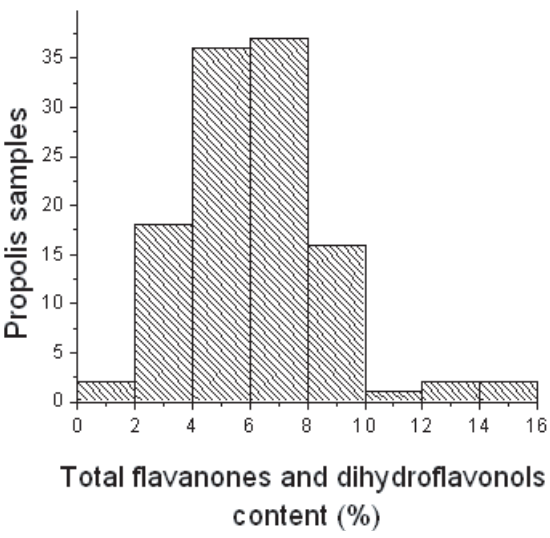

(d)

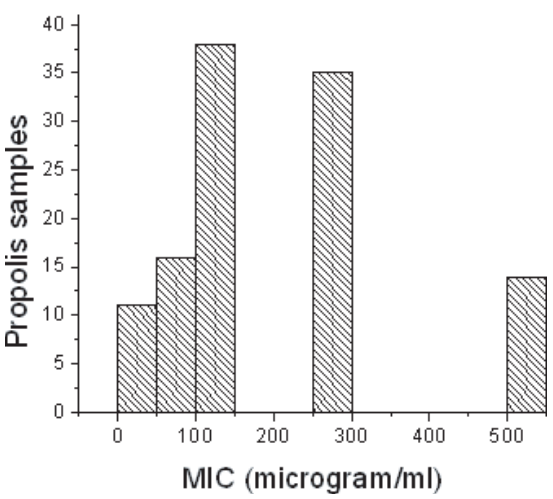

(e)

Figure 1. Histograms of the characteristics of poplar propolis (114 samples): A. Distribution of total balsam content; B. Distribution of total phenolics content; C. Distribution of total flavones and flavonols content; D. Distribution of total flavanones and dihydroflavonols content; E. Distribution of MIC. 
this reason, we formed two sample groups following other logic. Samples from Central and Southern Europe, Turkey, Syria and other locations within the Temperate Zone (97 samples) formed one group, and the second sample group combined samples originating from colder areas in the same zone, characterized by limited distribution of the source plant $P$. nigra: Northern regions and mountain regions (the Baltic countries, England, Ukrainia, Siberia, Canada, 7 samples, and Switzerland, 10 samples). ANOVA demonstrated that these two groups had significantly different $(P<0.05)$ phenolic and flavonoid contents. The content of the above-mentioned bioactive constituents was lower in the "northern and mountain" group by $25 \%$ for phenolics, by 38\% for flavones/flavonols and by $17 \%$ for flavanones/dihydroflavonols. However, these differences did not result in a statistically significant difference in the MIC for the two groups of samples $(P=0.23)$, although the value was lower by $17 \%$ for the northern and mountain propolis.

Further, there was significant negative correlation between the concentration of total phenolics in propolis balsam and the MIC $(P=0.003)$.

\section{DISCUSSION}

The large number of analyzed samples gave us the unique opportunity to statistically characterize poplar propolis with respect to its content of biologically active (antibacterial and antioxidant) compounds: total phenolics, total flavones and flavonols and total flavanones and dihydroflavonols.

Although the chemical composition of poplar bud exudates is relatively constant, there could be significant variations in the percentage of individual constituents in distinct locations or even in materials from different individual plants (Greenaway et al., 1990). These variations are reflected in propolis composition, shown in the table and the histograms (Fig. 1).

As the distribution was not normal, we propose to use the $20 \%$ empiric quantiles to set the minimum values for content of resin and biologically active compounds, and to use the $80 \%$ quantile for MIC. Choosing the $10 \%$ quantile would lead to low values for active components, and correspond to an unacceptably high value for MIC of $500 \mu \mathrm{g} \cdot \mathrm{mL}^{-1}$ (Tab. I). According to our results we suggest the following characteristics for a typical poplar propolis sample, which could be used as a basis for standardization and quality control:balsam, minimum $45 \%$; total phenolics, minimum 21\% (in raw propolis); total flavones and flavonols, minimum $4 \%$ (in raw propolis); total flavanones and dihydroflavonols, minimum 4\% (in raw propolis); and MIC against Staphylococcus aureus, maximum $250 \mu \mathrm{g} / \mathrm{mL}$ (prepared from dry balsam).

Samples from high elevations and high latitudes (mountains and northern regions) had significantly lower concentrations of biologically active substances in poplar type propolis but did not have significantly lower biological activity.

The significant negative correlation between the concentration of total phenolics in the resin and the MIC (the higher the concentration, the lower the MIC) was an important observation. Until now, no such correlation has been demonstrated using statistical methods. Bonvehi et al. (1994) studied correlations between the MIC and concentrations of various active propolis components and found that no individual compound surpassed Pearson-Lee values. Thus, the measurement of total phenolics is an important criterium of quality. The correlation of total flavones/flavonols and total flavanones/dihydroflavonols concentration with MIC was not found to be statistically significant $(P>0.1)$.

Our results show that measuring the concentrations of groups of active compounds of propolis, rather than individual components, is the appropriate approach to develop quality standards for propolis. Our results also indicate that because of the complex synergistic effects of different propolis constituents, measurement of MIC should be an obligatory element in quality control.

The results obtained in this study show that the chosen parameters are meaningful for the evaluation of poplar propolis quality. It is important to remember however, that other types of propolis have different chemical compositions (Bankova, 2005a). For this reason, all the above discussed conclusions and criteria are valid for poplar propolis only, and should by no means be applied to other propolis types, such as Brazilian green propolis or Cuban and Brazilian red propolis.

\section{Caractéristiques chimiques de la propolis de type peuplier de diverses origines géogra- phiques.}

Propolis / composition chimique / activité antibactérienne / standardisation

Zusammenfassung - Charakteristik von Pappelpropolis: Eine Studie über Proben 
unterschiedlicher geografischer Herkunft. Ziel dieser Arbeit ist, die typischen Eigenschaften von Pappel-Rohpropolis bezüglich des Gehalts an bioaktiven Komponenten (antimikrobiell und antioxidant) $\mathrm{zu}$ bestimmen. Hierzu wurden validierte spektrophotometrische Verfahren für die Quantifizierung der drei Hauptgruppen bioaktiver Substanzen (Phenole, Flavone/Flavonole, Flavanole/Dihydroflavonole) an 114 Proben unterschiedlicher geografischer Herkunft durchgeführt. Weiter wurde die Menge von Balsam (Extrakt mit $70 \%$ Ethanol) und die minimale Hemmkonzentration (MIC) gegen Streptococcus aureus gemessen. Die Messwerte für diese Charakterisierungen sind in Tabelle I. aufgeführt. Obwohl die chemische Zusammensetzung von Pappelknospenexudaten verhältnismäßig konstant ist, könnte es signifikante Abweichungen in dem Prozentsatz der einzelnen Komponenten an unterschiedlichen Orten geben (Abb. 1). Die Messwerte waren nicht normal verteilt, daher empfehlen wir die empirischen $20 \%$ Quantile zur Festsetzung des minimalen Balsamgehaltes und des Gehaltes an biologisch aktiven Komponenten, sowie des $80 \%$ Quantils für MIC. Hieraus ergibt sich für die Minimalgehalte im Einzelnen: Balsam $45 \%$, Phenole insgesamt $21 \%$ (im Rohpropolis), Flavone und Flavonole $4 \%$ (im Rohpropolis), Flavanone und Dihydroflavonole $4 \%$ (im Rohpropolis), und für MIC gegenüber Staphylococcus aureus ein Maximum von $250 \mu \mathrm{g} / \mathrm{mL}$ (im Trockenbalsam). Durch eine ANOVA konnte gezeigt werden, dass große Höhen sowie nördliche Breiten einen Einfluss auf den Gehalt an biologisch aktiven Substanzen haben, die Konzentrationen sind hier etwas niedriger. Allerdings ist dieser Einfluss von geringer Bedeutung, da er die biologische Aktivität der Proben nicht signifikant beeinflusste. Eine weitere wichtige Beobachtung war ein negativer Zusammenhang zwischen der Konzentration der Gesamtphenole im Propolisbalsam und MIC $(P=0,003)$. Bisher war ein solcher Zusammenhang nicht statistisch belegt. Die Ergebnisse sind für die Standardisierung von Propolis von besonderem Interesse. Sie unterstützen unser Konzept einer Vorgehensweise der Erfassung ganzer Gruppen bioaktiver Substanzen anstelle von Einzelkomponenten. Unsere Ergebnisse deuten weiter darauf hin, dass die Messung von MIC auf Grund der komplexen synergistischen Effekte der verschiedenen Propoliskonstituenten ein obligatorisches Element der Qualitätskontrolle sein sollte. Weiter ist wichtig daran $\mathrm{zu}$ erinnern, dass verschieden Propolistypen unterschiedliche chemische Zusammensetzung haben und die gezogenen Schlussfolgerungen daher nur für Pappelpropolis gelten und keinesfalls auf andere Propolissorten übertragbar sind.

Propolis / Pappel / Chemische Charakterisierung / antibakterielle Wirkung / Standardisierung

\section{REFERENCES}

Bankova V. (2005a) Recent trends and important developments in propolis research. Evid. Based Complem. Altern. Medicine 2, 29-32.

Bankova V. (2005b) Chemical diversity of propolis and the problem of standardization, $\mathrm{J}$. Ethnopharm. 100, 114-117.

Bankova V.B., De Castro S.L., Marcucci M.C. (2000) Propolis: recent advances in chemistry and plant origin, Apidologie 31, 3-15.

Banskota A.H., Tezuka Y., Kadota Sh. (2001) Recent progress in pharmacological research of propolis, Phytother. Res. 15, 561-571.

Bonvehi J.S., Coll F.V., Jorda R.E. (1994) The composition, active components and bacteriostatic activity of propolis in dietetics, J. Am. Oil Chem. Soc. 71, 529-532.

Castaldo S., Capasso F. (2002) Propolis, an old remedy used in modern medicine, Fitoterapia 73 (Suppl. 1), S1-S6.

Greenaway W., Scaysbrook T., Whately F.R. (1990) The composition and plant origin of propolis: a report of work at Oxford, Bee World 71, 107-118.

Greenaway W., May J., Scaysbrook T., Whatley F.R. (1991) Identification by gas chromatography-mass spectrometry of 150 compounds in propolis, $\mathrm{Z}$. Naturforsch. 42c, 111-121.

Hadjidimova D. (1975) Microbiological diagnostics, Medicina I Fiskultura, Sofia [in Bulgarian].

Kujumgiev A., Tsvetkova I., Serkedjieva Yu., Bankova V., Christov R., Popov S. (1999) Antibacterial, antifungal and antiviral activity of propolis from different geographic origin. J. Ethnopharmacol. 64, 235-240.

Marcucci M.C. (1995) Propolis: chemical composition, biological properties and therapeutic activity, Apidologie 26, 83-99.

Popova M., Bankova V., Butovska D., Petkov V., Nikolova-Damyanova B., Sabatini A.G., Marcazzan G.L., Bogdanov S. (2004) Validated methods for the quantification of biologically active constituents of poplar-type propolis, Phytochem. Anal. 15, 235-240.

Wollenweber E., Buchmann S.L. (1997) Feral honey bees in the Sonoran Desert: Propolis sources other than poplars (Populus spp.), Z. Naturforsch. 52c, 530-535. 